\title{
FREQUENCY ANALYSIS OF RAINFALL DATA OF DHARAMSHALA REGION
}

\author{
Nitish Kumar Sharma ${ }^{1}$ and Ashish Kumar $^{2}$ \\ ${ }^{1} M$. Tech student, Department of Civil Engineering, Jaypee University of Information Technology, Waknaghat, Solan (H.P.), India \\ ${ }^{2}$ Associate Professor, Department of Civil Engineering, Jaypee University of Information Technology, Waknaghat, Solan (H.P.), India
}

\begin{abstract}
The present study evaluates the rainfall magnitude for different return periods and also to ascertain the type of probability distribution that best fits the rainfall data of Dharamshala (H.P.), India. The study uses the 20 years of annual rainfall data that are useful for the prediction of annual one day maximum rainfall and two to seven days consecutive days maximum rainfall corresponding to return period varying from 2 to 20 years are to be used for the economic planning, by design engineers and hydrologists, design of small and medium hydrologic structures and determination of drainage coefficient for agricultural fields. Various probability distributions (viz: Normal, Log Normal and Gamma distribution) and transformations are applied to estimate one day and two to seven consecutive days annual maximum rainfall of various return periods in the Dharamshala (H.P.) region. The mean value of oneday annual maximum rainfall at Dharamshala is found to be $142.9 \mathrm{~mm}$ with standard deviation and coefficient of variation of 54.8 and 51.34 respectively. The coefficient of skewness is 1.1. For 2 to 7 days consecutive annual maximum rainfall range values for mean, standard deviation, coefficient of variation and coefficient of skewness are $201-393.4 \mathrm{~mm}, 70.17-146.5,41.65-30.47$ and $0.726-1.593$. It is observed that all distribution fitted function significantly.
\end{abstract}

\section{Introduction}

Analysis of rainfall and determination of annual maximum daily rainfall would enhance the management of water resources applications as well as the effective utilization of water resources. Probability and frequency analysis of rainfall data enables us to determine the expected rainfall at various chances. Such information can also be used to prevent floods and droughts, and applied to planning and designing of water resources related to engineering such as reservoir design, flood control work, soil and water conservation planning. The primary source of water for agricultural production for most of the world is rainfall. Useful for forecasting the floods to downstream towns and villages. Probability analysis of rainfall is necessary for solving various water management problems and to access the crop failure due to deficit or excess rainfall. Three main characteristics of rainfall are its amount, frequency and intensity, the values of which vary from place to place, day to day, month to month and also year to year. In general, three types of probability distributions (Normal, Log Normal and Gamma distribution) Walck (2007) are commonly used to determine the best fit probability distribution using the comparison of Chi-square, Anderson-Darling and Kolmogorov-Smirnov values. Therefore investigations were conducted in the past for study of the rainfall analysis by Suribabu et al. (2015), Olofintoye et al.
(2009), Bhakar et al. (2006), Nyarko et al. (2002), Singh et al. (2001), Rizvi et al.(2001), Mohanty et al. (1999), Upadhaya et al. (1998), among others.

\section{Methods and material}

Use Daily rainfall data recorded at Dharamshala (Himachal Pradesh) for a period of 20 years (1992-2012) by India Meteorological Department, Shimla (H.P.), India were used for this study. The daily data, in a particular year, is converted to 2-7 days consecutive rainfall of corresponding previous days. The maximum amount of 1-day and 2 to 7 consecutive day's rainfall for each year was then taken for the analysis.

\subsection{Statistical analysis of data}

The statistical behavior of any hydrological series can be described on the basis of certain parameters, generally mean, variance, standard deviation, coefficient of variation and coefficient of skewness were taken as measures of variability of any hydrologic series. All these parameters have been used to describe the variability of rainfall in the present study.

\subsection{Mean}

Mean represents measures of central tendency. Arithmetic mean is given by

\footnotetext{
${ }^{1}$ Corresponding author: nitish4sharma@gmail.com
} 


$$
\bar{X}=\frac{1}{N} \sum_{i=1}^{N} X_{i}
$$

Where,

$\bar{X}=$ mean

$\mathrm{Xi}=$ variate

$\mathrm{N}=$ total number of observations

\section{Standard deviation}

This parameter, as a measure of variability is most adoptable to statistical analysis. It is computed by

$$
S=\sqrt{\frac{\sum_{i=1}^{N}\left(X_{i}-\bar{X}\right)^{2}}{(N-1)}}
$$

Where, $\mathrm{S}=$ standard deviation

\section{Coefficient of variation}

This is a dimensionless dispersion parameter usually expressed as percent. It is given by

$$
C_{v}=\frac{S}{\bar{X}}
$$

Where, $\mathrm{Cv}=$ coefficient of variation

\section{Coefficient of skewness}

The coefficient of skewness was determined for each set of data from the formula given below:

$$
C_{s}=\frac{N^{2} M_{3}}{(N-1)(N-2) S^{3}}
$$

Where,

$\mathrm{Cs}=$ coefficient of skewness

$$
M_{3}=\frac{1}{N} \sum_{i=1}^{N}\left(X_{i}-\bar{X}\right)^{3}
$$

\section{Indentations and equations}

Goodness of fit (Dabral et al.)

Comparing the theoretical and sample values of the relative frequency of the cumulative frequency function can test the goodness of fit of a probability distribution. In case of the relative frequency function, the Chi-square test is used. The sample value of the relative frequency of interval $\mathrm{i}$ is calculated by the following equation:

$$
f_{s}\left(x_{i}\right)=\frac{n_{i}}{n}
$$

The theoretical value of the relative probability function is

$$
\mathrm{P}(\mathrm{Xi})=\mathrm{F}(\mathrm{Xi})-\mathrm{F}(\mathrm{Xi}-1)
$$

The Chi-square test statistic is given by the equation

$$
\chi_{c}^{2}=\sum_{i=1}^{m} n\left[\frac{\left(f_{s}\left(X_{i}\right)-P\left(X_{i}\right)\right)^{2}}{P\left(X_{i}\right)}\right]
$$

Where, $\mathrm{n}$ fs $(\mathrm{xi})=\mathrm{ni}$ is the observed number of occurrences in interval $\mathrm{i}, \mathrm{n} \mathrm{P}$ (xi) is the corresponding expected number of occurrences in interval $\mathrm{i}$

The $\chi^{2}$ distribution functions are tabulated in many statistics texts. In the $\chi^{2}$ test,

$\mathrm{v}=\mathrm{m}-\mathrm{p}-1$

Where, $\mathrm{v}=$ degree of freedom, $\mathrm{m}=$ number of intervals, $\mathrm{p}$ $=$ number of parameters used in fitting the proposed distribution

A confidence level is chosen for the test, it is often express as 1- $\alpha$, where ' $\alpha$ ' is termed as the significant level. A typical value for the confidence level is 95 per cent. The null hypothesis for the test is that the proposed probability fits the data adequately. This hypothesis is rejected if the value of $\chi_{c}{ }^{2}$ is larger than a limiting value, $\chi_{\mathrm{v}, 1-\alpha}^{2}$ (which is determined from the $\chi^{2}$ distribution with $v$ degree of freedom at $5 \%$ level of significance. Otherwise it was rejected.

\begin{tabular}{|c|c|c|c|}
\hline $\begin{array}{l}\text { Distrib } \\
\text { ution }\end{array}$ & $\begin{array}{l}\text { Probability density } \\
\text { function }\end{array}$ & Range & $\begin{array}{l}\text { Equation } \\
\text { for the } \\
\text { parameter } \\
\text { s in terms } \\
\text { of the } \\
\text { sample } \\
\text { moment } \\
\end{array}$ \\
\hline $\begin{array}{l}\text { Norma } \\
1\end{array}$ & $f(x)=\frac{1}{\sigma \sqrt{2 \pi}} e^{-\frac{1}{2}\left(\frac{x-\mu}{\sigma}\right.}$ & $\begin{array}{l}-2 \alpha \leq x \leq \\
\alpha\end{array}$ & $\begin{array}{l}\mu=x \\
, \sigma=S_{x}\end{array}$ \\
\hline $\begin{array}{l}\text { Log } \\
\text { Norma } \\
\text { l }\end{array}$ & $f(x)=\frac{1}{x \sigma \sqrt{2 \pi}} \exp \left(-\frac{(y-\mu)}{2 \sigma_{y}^{2}}\right)$ & )$_{\mathrm{x}}^{2}>0$ & $\begin{array}{l}\mu_{\mathrm{y}}=\mathrm{y} \\
\sigma_{\mathrm{y}}=\mathrm{S}_{\mathrm{y}}\end{array}$ \\
\hline $\begin{array}{l}\text { Gamm } \\
\text { a }\end{array}$ & $f(x)=\frac{\lambda^{\beta} x^{\beta-1} e^{-}}{T(\beta)}$ & $x \geq 0$ & $\begin{array}{l}\lambda=\frac{\bar{x}}{S^{2} x} \\
\beta=\left(\frac{\bar{x}}{S_{x}}\right.\end{array}$ \\
\hline
\end{tabular}

Probability analysis using frequency factors (Dabral et al.)

In case of Gamma distribution, frequency analysis was done by the method as described by Hann (1994) as given in Table-1

Table-1. Description of various probability distribution functions (Walck 2007).

Chow (1988) has shown that many frequency analyses can be reduced to the form

$$
\mathrm{X}_{\mathrm{T}}=\mathrm{X}\left(1+\mathrm{C}_{\mathrm{V}} \mathrm{K}_{\mathrm{T}}\right)
$$

For Normal and Log Normal distribution, the frequency factor can be expressed by the following equation (Chow, 1988) 


$$
K_{T}=\frac{X_{T}-\mu}{\sigma}
$$

This is the same as the standard normal variable $z$. The value of $z$ corresponding to an exceedance of $p(p=1 / T)$ can be calculated by finding the value of an intermediate variable w:

Where, $w=\left[\ln \left(\frac{1}{p^{2}}\right)\right]^{\frac{1}{2}}(0<\mathrm{p} \leq 0.5)$

Then calculating $\mathrm{z}$ using the equation

$z=w-\left[\frac{\left(2.515517+0.802853 w+0.010328 w^{2}\right)}{\left(1+1.432788 w+0.189269 w^{2}+0.001308 w^{3}\right)}\right]$

When $\mathrm{p}>0.5,1-\mathrm{p}$ is substituted for $\mathrm{p}$ in equation (10) and the value of $\mathrm{z}$ is computed by equation (11) is given a negative sign. The frequency factor $\mathrm{K}_{\mathrm{T}}$ for the normal distribution is equal to $\mathrm{z}$, as mentioned above.

\section{Figures and tables}

Statistical parameters of annual 1 day to 7 consecutive day's maximum rainfall

The statistical parameters of annual 1-day as well as 2 to 7 consecutive day's annual maximum rainfall are shown in Table 2. The mean value of one-day annual maximum rainfall at Dharamshala is found to be $142.9 \mathrm{~mm}$ with standard deviation and coefficient of variation of 54.8 and 51.34 respectively. The coefficient of skewness is 1.1. For 2 to 7 days consecutive annual maximum rainfall range values for mean, standard deviation, coefficient of variation and coefficient of skewness are $201-393.4 \mathrm{~mm}$ , $70.17-146.5,41.65-30.47$ and $0.726-1.593$. It is observed that all distribution fitted function significantly. On the basis of these tests, the results will be helpful in soil and water conservation planning and design of small and medium hydraulic structures such as small dams, bridges, culverts drainage works, etc. A common use of rainfall data is in the assessment of probabilities or return periods of given rainfall at a given location. Such data can then be used in assessing flood discharges of given return period through modeling or some empirical system and can thus be applied in schemes of flood alleviation or forecasting.

Table 2. Statistical parameters of annual 1 day to 7 consecutive day's maximum rainfall.

\begin{tabular}{|l|l|l|l|l|l|l|l|}
\hline $\begin{array}{l}\text { Parameter } \\
\text { s }\end{array}$ & $\begin{array}{l}\mathbf{1} \\
\text { day }\end{array}$ & $\begin{array}{l}\mathbf{2} \\
\text { days }\end{array}$ & $\begin{array}{l}\mathbf{3} \\
\text { days }\end{array}$ & $\begin{array}{l}\mathbf{4} \\
\text { days }\end{array}$ & $\begin{array}{l}\mathbf{5} \\
\text { days }\end{array}$ & $\begin{array}{l}\mathbf{6} \\
\text { days }\end{array}$ & $\begin{array}{l}7 \\
\text { days }\end{array}$ \\
\hline $\begin{array}{l}\text { Maximum } \\
(\mathrm{mm})\end{array}$ & $\begin{array}{l}279 . \\
6\end{array}$ & $\begin{array}{l}334 . \\
4\end{array}$ & $\begin{array}{l}397 . \\
2\end{array}$ & $\begin{array}{l}475 . \\
8\end{array}$ & $\begin{array}{l}574 . \\
0\end{array}$ & $\begin{array}{l}691 . \\
6\end{array}$ & $\begin{array}{l}770 . \\
4\end{array}$ \\
\hline $\begin{array}{l}\text { Minimum } \\
(\mathrm{mm})\end{array}$ & 84.1 & $\begin{array}{l}104 . \\
8\end{array}$ & $\begin{array}{l}128 . \\
7\end{array}$ & $\begin{array}{l}156 . \\
9\end{array}$ & 203 & $\begin{array}{l}218 . \\
4\end{array}$ & $\begin{array}{l}240 . \\
9\end{array}$ \\
\hline $\begin{array}{l}\text { Mean } \\
\text { (mm) }\end{array}$ & 142. & 201. & 241. & 287. & 325. & 364. & 393. \\
\hline $\begin{array}{l}\text { Standard } \\
\text { deviation } \\
\text { (mm) }\end{array}$ & 9 & 0 & 4 & 6 & 5 & 4 & 4 \\
\hline $\begin{array}{l}\text { Coefficient } \\
\text { of }\end{array}$ & 51.3 & 41.6 & 37.1 & 34.5 & 32.7 & 31.4 & $\begin{array}{l}30.4 \\
7\end{array}$ \\
\hline
\end{tabular}

\begin{tabular}{|l|l|l|l|l|l|l|l|} 
variation & & & & & & & \\
\hline $\begin{array}{l}\text { Coefficient } \\
\text { of } \\
\text { skewness }\end{array}$ & & & & & & & \\
& & 0.72 & 0.88 & 0.78 & & 1.27 & 1.59 \\
\end{tabular}

Fitting of various probability distribution functions One day annual maximum, 2 to 7 consecutive days annual maximum rainfall data in its original form was fitted to different probability distribution function i.e. Normal, Lognormal. As per the Chi-square value, Log Normal distribution function is found to be best fit function for 1 to 3 days and 7 days annual maximum rainfall data. The computed Chi-square values for the probability distribution i.e. Normal, Log Normal and Gamma are found to be less than the critical value of Chisquare at $95 \%$ confidence level for 1 day as well as consecutive days maximum rainfall series. The statistical comparison by Chi-square test for goodness of fit clearly shows that Log Normal distribution is the best fitting representative function for rainfall frequency analysis in this region.

Table 3. Formatting sections, subsections and subsubsections

\begin{tabular}{|l|l|l|l|}
\hline Consecutive days & Normal & $\begin{array}{l}\text { Log } \\
\text { Normal }\end{array}$ & Gamma \\
\hline 1 Day & 1.20 & 4.83 & 2.08 \\
\hline 2 Days & 1.04 & 2.19 & 6.59 \\
\hline 3 Days & 3.67 & 1.86 & 1.53 \\
\hline 4 Days & 1.68 & 1.14 & 2.44 \\
\hline 5 Days & 3.78 & 1.23 & 7.12 \\
\hline 6 Days & 1.82 & 2.34 & 2.64 \\
\hline 7 Days & 6.35 & 3.72 & 5.09 \\
\hline
\end{tabular}

The graphical plot as shown in figure 1 below shows one day annual maximum, 2 to 7 consecutive day's annual maximum rainfall data was fitted to different probability distribution function i.e. Normal, Lognormal and Gamma. The results of this study would be useful for agricultural scientists, decision makers, policy planners and researchers in order to identify the areas where agricultural development and construction of drainage systems takes place.

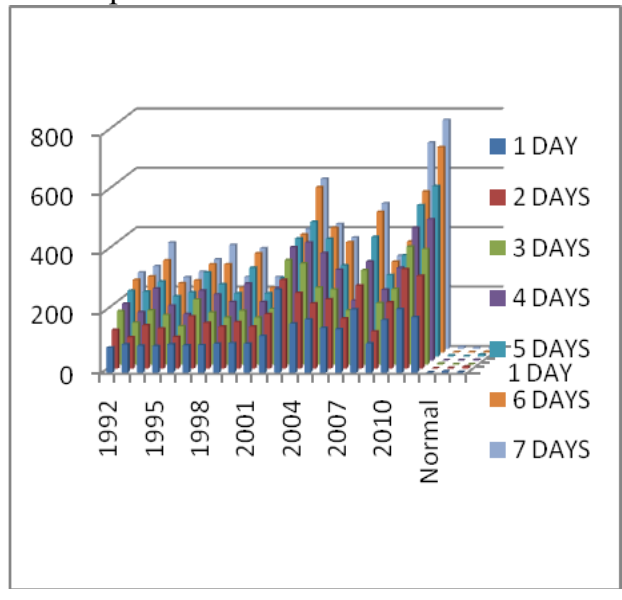

Figure 1. Graphical plot showing Chi-square values for different distribution 


\section{Conclusion}

1. The mean value of one-day annual maximum rainfall at Dharamshala is found to be $142.9 \mathrm{~mm}$ with standard deviation and coefficient of variation of 54.8 and 51.34 respectively. The coefficient of skewness is 1.1. For 2 to 7 days consecutive annual maximum rainfall range values for mean, standard deviation, coefficient of variation and coefficient of skewness are $201-393.4 \mathrm{~mm}$ , $70.17-146.5,41.65-30.47$ and $0.726-1.593$. It is observed that all distribution fitted function significantly. 2. It is observed that all distribution fitted function significantly.

3. The study of frequency analysis will be used as a rough guide by engineers and hydrologists to prevent floods and droughts, and applied to planning and designing of water resources related to engineering such as reservoir design, flood control work. Analysis of rainfall and determination of annual maximum daily rainfall would enhance the management of water resources applications as well as the effective utilization of water resources. The results of this study would be useful for agricultural scientists, decision makers, policy planners and researchers in order to identify the areas where agricultural development and construction of drainage systems takes place.

\section{Acknowledgements}

Authors are sincerely thankful to Indian Meteorological Department, Shimla (H.P.) for providing the 20 years (1992-2012) daily rainfall data for present study.

\section{References}

1. Suribabu, C. R., Sudarsan, J. S., Ramanan, S. R. " $A$ study on consecutive day maximum rainfall for disaster mitigation in Tiruchirapalli City, India." JJCE, 9(2), 197-202, (2015)

2. Olofintoye, O. O, Sule, B. F. and Salami, A. W. "Best-fit Probability distribution model for peak daily rainfall of selected Cities in Nigeria." New York Sc. Journal, 2(3), 1554-2000, (2006)

3. Bhakar, S. R., Bansal, A. N. Chhajed, N. and Purohit, R.C. "Frequency analysis of consecutive day's maximum rainfall at Banswara, Rajasthan, India." ARPN Journal of Engg. And Applied Sc., 1(3), 64-67, (2006)

4. Nyarko, K.B. "Application of rational model in GIS for flood risk Assessment in Accra, Ghana." Journal of Spatial Hydrology, 2(1), 12-14, (2002)

5. Singh, R. K. "Probability analysis for prediction of annual maximum daily rainfall of Eastern Himalaya (Sikkim Mid Hills)." Indian Journal of Soil conservation, 29(3), 263-265, (2001)

6. Rizvi, R. H., Singh, R., Yadav, R. S. Tewari, R. K. Dadhawal, K. S. and Soolanki, K. R. "Probability analysis of annual maximum daily rainfall for Bundelkhand region of Uttar Pradesh." Indian Journal of Soil Conservation, 29(3), 259-262, (2001)
7. Mohanty, S. Marathe, R. A. "Probability analysis of annual maximum daily rainfall for Amravati. " Indian Journal of Soil Conservation, 43(1), 15-17, (1999)

8. Upadhaya, A. and Singh, S. R. "Estimation of consecutive days Maximum Rainfall by Various Methods and their Comparison." Indian Journal of Soil Conservation, 26(2), 1993-2001, (1998) 